healthy man is much disputed, notwithstanding that the older physicians attributed to the secretion of the sudoliparous glands a definitely depurative action. This question can only be put to the test by injecting into the blood of animals suitably chosen sweat secreted by healthy human subjects. In consequence probably of the difficulty encountered in procuring the reagent the question has been attacked by very few experimenters. So far as I am aware Röhrig and Queirolo alone have experimented with injections of sweat. The first named, who made only a single injection upon a rabbit, came to the conclusion that the effect was toxic; the second, who made fourteen injections, thinks that the sweat of healthy persons does not eliminate any toxic substance. I have thought it necessary to renew the study of this subject, and have obtained the elements of sweat by divers processes and many specimens of normal sweat. thanks to the coöperation of $M$. Berthe and Dr. Sonrel. The experiments have accordingly been very various. From all these experiments I have come definitely to the conclusion that toxic matters are present in the sweat of a healthy man. Injected into the blood sweat causes the death of a dog following upon an average dose of 15 c.c. per kilogramme of the living animal; of a rabbit with a dose of 25 c.c. after an interval of from twenty-four to sixty.two hours. It will also kill a guinea-pig if introduced in a sufficient dose subcutaneously into the peritoneum or the connective tissue. Although I have not yet produced immediate deatb, the injections always occasion an illness of a certain duration. The duration of the illness, the gravity of the symptoms, and the dose necessary to cause death vary with the conditions under which the sudoriparous glands have performed their functions. For instance, sweat secreted under violent muscular exertion possesses a toxic efficacy exceeding by one-fourth or even by one-third part the ordinary toxicity. Furthermore, other things being equal, sweat obtained by artificial sudorific means exhibits a minimum of toxicity.

The toxicity of normal sweat being established, I proceeded to ascertain the nature of the poisoning, and take for illustration the troubles experienced by a dog. As a general rule the introduction into the jugular vein of the first quantities of sweat occasions a lively excitement, quickly followed by a remarkable sedative effect, which continues throughout the course of the injections. The dog is thrown into a state of the most complete calm, the eyelids are half-closed, under the influence as might be supposed of a narcotic; but it is nothing of the kind, for the dog briskly regains its feet if set at liberty. Very soon it becomes profoundly miserable. The principal muscles are attacked by tremblings. The eyes are tearfal. At this stage the temperature is notably elevated, and it may be observed that the dog is attacked by disorders of the digestive system, such as repeated romitings, at first alimentary, afterwards bilious; abdominal pains; diarrhœic stools ; strainings (épreintes), and sometimes slight intestinal hæmorrhages. The breathing is short and rapid. The beating of the heart, much accelerated at first, resumes after some hours its ordinary rhythm; then it becomes accelerated afresh and gradually feebler. The arteries are soft and compressible and the pulse is barely perceptible. The extremities become cold, the animal grows indifferent to its surroundings, its prostration becomes extreme, it temperature falls below the normal, and finally it succumbs after having exhibited a series of symptoms which strikingly recall those that follow upon the administration of certain microbic toxins. When the poison does not assume this aggravated form the malady lasts for several days. The animals manifest an improvement at the end of four-andtwenty hours-a transient improvement, followed by a moderate degree of fever, loss of appetite, profound exhaustion, and sometimes a loss of power in the members bordering on paralysis. In this case, as in the preceding the subject succumbs with subnormal temperature. If the dose of sweat injected is less strong or the subject more resisting two results may follow: the animal may recover completely or it may fall into a cachectic condition which carries it off in the space of from fifteen to thirty days.

Having thus given a summary account of sweat poisoning I propose to give details of some of the principal disturbances. In this note I will deal with the troubles arising to the circulation which I have studied minately

2 Vide Comptes Rendus de la Société de Biulogie, séances du 19 Décembre, 1896, et du 29 Mai, 1897. with the aid of the graphic method. When first introduced in to the blood the sweat produces disturbances of which the intensity varies with the degree of toxicity or of concentration. They are exhibited from ten to twenty seconds after the $c$ mmencement of the injection. Amid manifestations of excitement, cries, and complaints, the pulse suddenly becomes small and accelerated; from 120 pulsations a minute it mounts to 240 and 300 ; simultaneously the arterial pressure rises and attains sometimes $200 \mathrm{~mm}$., then rapidly falls to about $70 \mathrm{~mm}$. Considering the rapid descent of the curve and the smallness of the palse one begins to fear for the life of the subject, and this the more since these sym. ptoms usually coincide with irregular and superficial respiration. With certain animals and certain kinds of sweat these troubles are less acute, and being more moderate they are more easy to observe. They are least when the sweat employed is a secretion obtained artificially after long repose. This crisis is feeble or absent after subsequent injections. The crisis over, the pressure gradually falls and reaches a point below the initial pressure; the heart becomes. calm and beats with greater energy, so that after an hour or an hour and a half the circulation is no longer disturbed in proportion to the gravity of the situation. But if the animal be left to itself for eight or ten hours, and then the arterial system be again examined by means of graphic apparatns, a considerable fall of arterial pressure and acceleration and enfeeblement of the pulse will be detected. Thus, in one experiment before injection the pressure amounted to $176 \mathrm{~mm}$. of mercury and the pulse was 96 . One and a half hours after the injection of the poison the pressure had fallen to $160 \mathrm{~mm}$. and the pulse had gone up to 120 . Nine hours later the pressure was $110 \mathrm{~mm}$. and the pulse 156. This noticeable change in the pressure, pulse, and heart coincides with the phase of prostration and with the establishment of an abundant sero-sanguineous exudation (exhalation sérosanguinolente) upon the gastro-intestinal mucous membrane rather than with any general phenomenon of vaso.motor dilatation. I have observed that at the moment of most severe distress in the circulatory system, when the pulse is most accelerated, the excitability of the moderating nerves of the heart remains intact. The sudoral poison therefore acts chiefly upon heart exciting centres and the muscular fibre of the heart.

In a subsequent note I propose to examine the disturb. ance occasioned to other important functions.

\section{IMMORALITY AMONG SCHOOL BOYS.}

\section{By MaUrice C. Hime, M.A., LL.D.,}

SOMETINE HEAD MASTRR OF FOYLK COLIEGE, LONDONDRRRY.

I RECEIVED so many letters concerning the special form of immorality indicated in the above heading from readers of THE LANCET since the appearance of a letter signed "Father" in its columns, ${ }^{1}$ that it seems to me to be of sufficient general interest to justify me in asking for space wherein to express the result of my thirty years' experience as a head master in regard to this vice at somewhat greater length than I could conveniently adopt in a letter to each of my several ccrrespondents.

I will speak, first, of the prevalence of the rice in boys' schools; next, of the duty of headmasters regarding it; thirdly, of the best means of preventing and checking it; and I will conclude with a few words of encouragement to the educator, whether schoolmaster or father, who strenuously exerts himself, with the help of God, to safeguard the boys entrusted to his charge from the sin in question.

That the vice exists, to a greater or less degree, wherever many boys are gathered together under one roof, who with any knowledge of boys will deny? Some schoolmasters bare spoken to their pupils on the subject; others have written pamphlets about it for private circulation; others have urged fathers to caution their sons concerning it before sending them to school ; purity societies have issued leaflets that can be purchased at their offices; and medical men have published books, numerous and important, on its cause and cure. And yet, the above facts notwithstanding, hundreds of head masters go on year after year as if blind to this trutb, 
ignorant or affecting to be ignorant of it. It is so painful to believe. As well expect a neglected garden to be free from weeds as a school managed by one of these " blind guides" to be free from this vice. How absurd to suppose that the devil, who forced his way into Paradise, will not force his way also into boys' schools, most of all into those schools the head masters of which "having eyes see not, having ears hear not, neither do they understand"!

The prevalence of this vice in most boys' schools may accordingly be taken for granted. This then being so, it follows that every professional edacator is plainly bound by the duties attaching to his office to endeavour by all means in his power to defend his pupils, and help them to defend themselves, from this and every other pollution. Educator I say, rather than schoolmaster ; for a schoolmaster's duty is far more, be it noted, than merely to instruct his pupils in classics, mathematics, and the other school subjects. "Ob, but let fathers warn their sons of the prevalence and deadly rature of this vice before sending them to school. It is their duty to do so." Undoubtedly, it would be satisfactory if fathers were to forewarn their sons of the terrible temptations and dangers awaiting them at school, showing them how these temptations may be best resisted, and pointing out to them the fearfal consequences of yielding to them. As a general rule, however, boys are not forewarned on the subject, as schoolmasters are only too well aware. Are schoolmasters, therefore, themselves to neglect warning them because their fathers have done so? Is A to shirk his duty because B shirks his? Furthermore, there are some boys whose fathers are dead; others whose fathers are dall, coarse, and indifferent, not caring a straw how their sons conduct themselves at school; others whose fathers are themselves eensualists of the commonest type; others whose fathers are so particularly fastidions, so hyper-sensitive, as to be unable, or at least unwilling, to speak to their sons on such an unsavoury subject. And what of the sons of such parents as any of the above? In short, it is all nonsense a schoolmaster's trying to evade his own obvious duty and impose it on someone else. By his own voluntary undertaking, of his own freewill and accord, the schoolmaster professes to develop the religious and moral as well as the intellectual faculties of his pupils, for the performance of which duty he receives, not only fees from their parents, but also in many casea an endowment, as headmaster of the school, as well. The schoolmaster who does not faithfully discharge this his manifest duty is indubitably an unfaithful steward, and ntterly unworthy of the noble, self-sought name of educator.

As to the best means of preventing and checking this vice opinions will differ. The following I personally have found effectual. I will divide them into $A$, school arrange. ment; and $B$, moral suasion.

A.-1. Cubicles I would have none of. The dormitories in Foyle College had been fitted up with cubicles shortly before my appointment as headmaster, but I insisted on their being removed before I undertook the duties of my office. Cubicles I regard as mere inventions of Satan the better to enable boys, weak-minded or sensually disposed, secretly to indulge in odious habits. Cubicles are, besides, productive of increased dust, dirt, gloominess, disagreeable smells, and defective ventilation. Well ventilated, airy dormitories, with rows of beds, not too close, that can be all seen at a glance by the superintending master, with a master's bedroom at opening of each dormitory, were an essential part of my system; besides, the manly and good boys, who are always in a considerable majority in every well-regulated school, render in such dormitories the practice of this vice well - nigh impossible. Such odiousness would not be tolerated by them for a moment. But where there are cubicles it can, obviously, go on with inopunity, unchecked, in secret, no matter how excellent the tone of the school may be. 2. Lying in bed in the morning - "soaking," as the boys express it - was discountenanced in every way. At a certain hour every morning the bell for getting up rang, and the moment it rang it was the duty of the master in charge to oblige the boys to get up-on Sundays and holidays just as promptly as on working days. The prolonged enjoyment of luxurious sloth is apt to demoralise even the best-disposed. 3. A suffciently large staff of masters to enable me to have one or another of them always on duty during play hours was another essential part of my system. The companionship of a suitable master was always agreeable to the boys. He helped them with their games, prohibited loafing, ballying, filthy conversation, profane language, and other juvenile misdemeanours, while his very presence made smoking an impossibility. On the injury done to the growing brain and growing body of a little boy by the use of tobacco I need not dwell, neither need I dwell upon the sneaking, underhandedness, falsehoods, deceptions, misspending of pocket money, with the common results of such mis-expenditure, inseparable from indulgence at school in the forbidden weed. 4. Intimacies between older and younger boys were discouraged. I seldom or never observed such a friendship springing up without suspecting that, in all probability, the younger boy was being injured by the older one-instructed or misinstructed in forbidden things, rendered conceited, spoilt for companions of his own age, and so forth. 5. The letting out of boys during school-hours "for a minute," as the request to go out is generally worded, was reduced to a system. Only one boy was let out at a time, and on one master, and that my principal master, devolved the duty of giving or refusing, according to his discretion, the asked-for permission. The boy was expected not to remain outside for more than three or four minutes at the very most. Going out during school-hours was, in short, a good deal discountenanced. Boys were trained to expect that they would generally be required to remain in the schoolroom for as long, say, as a two bours' railway journey, or an ordinary Sunday mcrning church service. Think of the iniquities that have been transacted by boys in privies at schools where little or no vigilance was exercised by those in authority in regard to the number and the characters of the boys let out at once, or the length of time that they might stay out! The card playing, drinking, shameful bullying, and beastliness of $\epsilon$ very kind! I speak now from my own personal experience as a boy, and that in more than one school. The longest continuous period of class instruction-three hours-I broke up in the middle by permitting, or rather compelling, every boy then to leave the school for ten minutes' relaxation, during which period the doors and windows were all opened wide for ventilation purposes. Concerning the conduct of the boys during these ten minutes $I$ entertained no misgivings. There is safety in a multitude, and all the more so when the great mass of the multitude is right-minded and well-disposed. When the great mass of the boys in a school is not right-minded and well-disposed there must be something strangely amiss in the head master; he would certainly not appear to me to be the right man in the right place. 6. Occupation of some sort, whether in the playfield or, on a wet day, in or about the school, was insisted on. Out-door games were obligatory on all boys except those forbidden them by a medical man-an exceedingly small, but usually most troublesome, minority. Where out.door games are not compulsory there there will be loafing. Where there is loafing, there impure thoughts-if not filthy acts and filthy talking - will be indulged in. The letting off of superfluous energy by means of out-door games - long walks being substituted for these games on Sundayscontributes much to the suppression of the lusts of the flesh in boy and man alike. "That Satan finds," \&c., is a proverb that, where schoolboys are concerned, contains so much solemn truth that one wonders how it is that any schoolmaster can ever endure to see his boys loafing about unoccupied. "Work or play," "Labour or refreshment," should be the motto of every school. Boys thus incessantly occupied have no time for impurity, no desire for impuritynone, at least, compared with that pervading the hearts of the unemployed. 7. Reading during play hours was not allowed. The reading of fiction, except such fiction as the boys' mothers or sisters might safely read, was not allowed at any time. The mischief done to boys by the reading of highly sensational immoral literature is incalculable. 8. There was a rule in $m y$ prospectus that "The trousers must have no pockets in them." To see boys sitting or slouching about continually fumbling with their hands in their trousers' pockets or, only a degree worse, between their trousers and their skin or shirt, was more than I could endure with unruffled temper. The objections to the babit are obvious; it is dirty, disgusting, loathsome, ungainly. So far for the school arrangements. And, with much respect, I would like to add that, quite apart from their special bearing on the vice treated of, these arrangements will not be found unprofitable in any school.

$B .-$ As to the moral suasion method, I on one occasion seriously addressed the boys when all specially assembled together, concerning this secret, unmentionable sin. I spoke 
to them at once so pointedly that the guilty boys all quickly understood what I was speaking about, yet so generally that none of the others did. They only knew that I was speaking about something awful, and that the less thought or spoken about it the better. I explained to them how that a vice to which some misguided boys were addicted was (a) a sinimpurity of every kind, the impure thought and look as well as the impure act, being forbidden by Jesus ; $(\beta)$ unnatural - the best part of our nature, conscience, being ntterly opposed to it, as was also self-love; and $(\gamma)$ followed, if persisted in, by the most injurious, sometimes even fatal, physical consequences, such as irritability of the entire nervous system; debility, general or local ; injury, irremediable to the sexual organs; overmastering, lustful desire ; impotency ; insomnia ; insanity ; idiotcy-although these consequences may be sometimes slow in overtaking the sinner; that, further, the utter deterioration of one's spiritual and moral natures also resulted from indulgence in this sin, sin thus leading on to more and ever more sin. On each of these points I dwelt at some length so as to make them, one and all, perfectly clear to those especially addressed. $I$, further, explained to them that we schoolmasters were not slow in recognising those guilty of this pernicious self-indulgence; that reverie at class, dislike to out-door games, moping, defective memory, a disinclination to look at one straight in the face, usually mark out these self-polluters. I implored of them to pray to their Heavenly Father, with all the sincerity of which they were capable, and that not once only but every morning and every evening of their lives, that the meditations of their heart, the words of their mouth, and all their acts might be always acceptable in His sight. I entreated of them to take the pledge, as it were, against this accursed sin-a sin so destructive of soul and mind and body alike. I begged of them to busy themselves always with some lawful, innocent occupation, an iajle brain being, as they themselves knew, so abundantly prolific of evil thoughts. And, finally, I explained to them what efforts my masters and I were making so as to render it the more easy for them to eschew the terrible evil, telling them the meaning of the different school arrangements that had been made with this object in view, and beseeching them to fall in with these arrangements in the same spirit as that which prompted me in making them, for that I felt sure that, with my boys on my side, Satan could be effectually resisted, but that without their willing assistance my efforts must be, to a great extent, in vain. The boys listened to my address with breathless attention, all of them, with the exception of a few little boys who were evidently innocent of the sin, and did not understand to what exactly I was referring. Boys, I have generally found, not only listen attentively to such warning, but are most grateful for it. Many of them have indulged in the vice without fully realising its exceeding sinfulness, or being in the least aware of the evil consequences, especially as these are so often slow in manifesting themselves. Even when, as sometimes happens, the evil consequences do quickly overtake one guilty of this sin, they are frequently misunderstood, and often assigned to a totally wrong cause.

Such was the tenor and gist of my general address, but my efforts did not end here. To new boys coming subsequently to the college I spoke separately on the same lines, more or less distinctly according to the sort of boy each was and his age. Eren the youngest and most innocent boy, I felt, could not but be benefited by being warned generally of the possible temptations awaiting him; of the best means of avoiding and resisting them; and of the injurious effects of sinful self-indulgence of every kind. "But is it not possible that such plain-speaking may do actual harm to the innocent boy?" No; good advice, given at once wisely and affectionately by an experienced and discreet schoolmaster, cannot, I venture to reply, do harm to any boy, good, bad, or indifferent-least of all to the first-named, the innocent boy, who had grown up to boy's estate without, we are supposing, ever dreaming or hearing of this abominable sin. At all events, I, personally, cannot recall any instance of a boy being injured by such warning; whereas I have known numerous instances of boys being immensely benefited by it. The greatest good of the greatest number is, in any case, the object at which we all should aim; and, obviously, there is no way of dealing with this, or any other prevalent sin, at which someone might not be found to cavil. And one thing is clear-this even objectors to the system herein recommended will themselves admit-that, whatever the best course to be adopted in dealing with this abominable practice may be, the usual silent system, the ignoring of the vice as though it did not exist at all, has been the source to mankind of infinite mental and bodily suffering.

Expulsion of the boy reasonably suspected, or actually detected, is the plan adopted by some schoolmasters-an absurd, injurious, and most unfair plan in my opinion. For in the first place the expelled boy may have been by no means the worst or single offender in the school; and accordingly the only effect of the expulsion may be, (a) so far as he is concerned, to mar materially his prospects in life, while of his odious self-indulgence be may not be in the least degree cured; and, (b) so far as the other boys are concerned, those not detected, to 'induce them to go on in their sinful ways, only more secretly than ever. For so long as even one boy in a school practises the vice, it is likely to spread. And how much more likely in a school the head master of which is satisfied to believe that the expulsion of a boy and the purifying of his school mean one and the same thing, and that with the expulsion his efforts after purity may be securely relaxed. Bad weeds grow apace, and a single diseased sheep may taint a flock of thousands. In the next place, the expelled boy or boys may be, in reality, the cleverest in the school, and even, only for their indulgence in this accursed practice, the most promising. Thus the school may have in reality lost rather than gained by the expulsion-expulsion for the contracting of an evil habit of which, wretched boys, perhaps they never heard until they went to the very school from which they are now turned out as outcasts! Moreover, it was assuredly to. heal those that were sick-a fact apparently forgotten by these expelling schoolmasters - to call sinners to repentance, that Jesus came. What right, then, has a schoolmaster to attempt to wash his hands of the anxiety and trouble inseparable from his profession, properly understood? What right has he to pretend to retain as pupils in his school those boys only who in his opinion-an opinion for which there is rarely any sure foundation- " need no repentance"? A boy once desired to speak to me privately in my stady. In real tribulation he assured me that since he came to the school, some months previously, he had never committed the sin of which I spoke to him on his arrival, but that every night he had most disturbing dreams-a doctor can guess all the rest of his admissionsand that he felt very ill, and thought he had better come and tell me; and that he hoped I would not expel him. "Expel you, my poor boy!" I said, "No, God help you! You have already, surely, been visited with sufficiently severe punishment-the punishment that has naturally followed your sinful conduct. I will call in the school physician, and we will see what can be done to relieve your sore sufferings and trouble." The outcome of the interview, briefly, was this : after the lapse of some months, this boy, almost quite recovered from his alarming infirmity, was one of the best behaved and most generally popular boys in the school-thoroughly trustworthy, first-rate at games, attentive at class, and diligent during preparation hours.

It should be a great encouragement to the schoolmaster, who leaves no stone unturned to eradicate this vice from his school, to remember that it is not boys only whom he his safeguarding against mental and bodily pollation, but men also. And what a scourge to themselves and to others impure men are! The purer the boy the purer the man. Similarly, the more impure the boy the more impure the man. Habit is a second nature. The boy who unwarned, undetected, uncensured, has secretly practised this abominable vice for years and years together, and so stimulated, unnaturally, the lusts of his flesh, is just the person, when he becomes a man, to yield to every temptation to gratify these lusts ; that is, assuming that he has not damaged beyond cure his virile powers by the self-abuse he indulged in as a boy. "What is the harm of sexual gratification?" the youth who has deadened his conscience by self-abuse at school is likely to ask himself : "I never was told it was either sinful or injurious all the time I was at school." The undisciplined, ill-trained youth thus begins life at an immense disadrantage, caused by the supineness and blindness of his schoolmaster, whose bounden duty it unquestionably was to hare explained to him the sinful nature and destructive effects of this vice. The boy, on the other hand, who has been accustomed to keep his passions under due control, and enters life, whether the university or a bigger world still, with a sound mind in a sound body, innocent, jet properly instructed as to the unnaturalness, the sinfulness, and the pernicious consequences, slow but sure, of this deadly $\mathrm{sin}$, 
is likely, if anyone is, to keep his body, when be becomes a man, in temperance, soberness, and chastity unto his life's end.

Cluain Fóis, Bunerana.

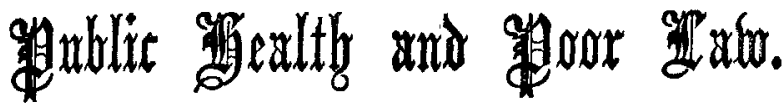

\section{LOCAL GOVERNMENT DEPARTMENT.}

BEPOBTS OF MEDICAT OFFICERS OF HEALTH.

Sunderland Urban District.-Dunderland has a notoriety for enteric fever, and it is to this subject that Dr. Harold Scurfield devotes considerable space in his annual report. During 1896 there were but two of the thirty-three great towns that had a higher death-rate from enteric fever than had Sunderland. Wolverhampton heads the list with a death-rate of 0.41 per 1000 . Bolton follows with a rate of 0.39 , and Sunderland with one of 0.37 . In, too, the matter of diarrhœe Sunderland is in bad company, but its rate in this respect is exceeded by Wolverhampton, Leicester, Salford, Birmingham, Liverpool, Preston, Bolton, Sheffeld, and Hull. It appears that the excessive incidence of enteric fever in Sunderland began to manifest itself about 1889, and after a sudden drop in the wet cold summer of 1894 it reached the highest rate yet recorded in 1895, but in this year it has to be noted that a considerable amount of the increase was due to a milk epidemic. Dr. Scurfield finds that, taking the average rates for diarrhcea and enteric fever since the year 1888, the greatest number of deaths from the former disease occur in the thirty-fourth week of the year, while for enteric fever the maximum figure is reached in the thirty-sixth week; and in a very interesting special report which he has presented to the sanitary authority of his district Dr. Scurfield shows that during 1890-95 enteric fever was more prevalent in towns in which privy-middens largely obtained than in towns where the excrement was removed by means of water carriage, and on examining the figures for 1896 he finds that the same rule holds gond. "Privy-midden towns" are regarded as those in which the number of privy. middens approximates or exceeds 5 per cent. of the population. Dr. Scurfield observes that the bacillus of enteric fever, being capable of resisting frost, can, when thrown on to a privy, live in the soil throughout the winter, and propagate itself when the ground gets hot in the ensuing summer, and he furnishes in his report instances where probably this phenomenon has occurred and where certain houses and even streets have become again and again invaded by enteric fever. Although the privies are nominally disinfected it is obvious, as Dr. Scurfield observes, that the chances of really destroying all the infection which may lie in the surrounding soil are remote in the extreme. To sum up, Dr. Scurfield urges that the privies are largely responsible for the enteric fever of Sunderland for the following reasons : Negatively, there is no reason to suspect the water-supply, the milk supply (save for a certain period of 1895), or the sewers as cause. Positively, it is found that enteric fever is more prevalent in privy-midden towns than in water-closet towns, and in towns where both systems of excrement disposal are in use the chief incidence of enteric fever is found in the houses and districts provided with privy-middens. Furthermore, certain houses and streets in Sunderland where the privy-midden system is in rogue have been frequently re-invaded by the disease. It is interesting to note in reference to the relation of prevalence and type of enteric fever in Sunderland that during 1895 there were 840 cases, with a fatality rate of 15.4 per cent., while in 1896 the 260 cases yielded a fatality rate of 20.8 per cent. As a sort of sequel to Dr. Scurfield's interesting report he and the borough engineer have made an estimate of the saving to the cleansing department of the borough which will accrue from the general adoption of the water-carriage system in Sunderland.

St. Helens Urban District.--Dr. John Robertson has recently made some very interesting and instructive observations upon the behaviour of enteric fever, and a notice of them may appropriately follow that of Dr. Scurfield's report, which we have just considered. As in the case of Sunderland, the notifications of enteric fever in St. Helens during 1896 were relatively small, while the deaths were relatively large in number. Dr. Robertson has calculated from the weekly returns from certain large towns which are sent to the Local Government Board the sickness rates from enteric fever per 1000 of the population in the thirty-one towns in question. It seems that in the matter of sickness incidence St. Helens, with a rate of no less than 2.07 per 1000 , easily takes the lead, the next highest being Sheffield, with one of 1.81 per 1000. The lowest rate is that of Plymouth, 0.31 per 1000. As regards the seasonal prevalence of the disease at St. Helens a chart is given in the report before us which shows the weekly number of cases in relation to the temperature of the soil at a depth of four feet and of the air. Dr. Robertson has now furnished these charts in his reports for some years, and they show a distinct relationship in point of time between the prevalence of enteric fever and the temperature of the earth at a depth of four feet. Allowing a period of three weeks as a reasonable average time between the ingestion of the poison and the notification of the disease, it is found that from 1892 to 1896 inclusive enteric fever became prevalent in St. Helens three weeks after the soil temperature at four feet had risen to $52^{\circ} \mathrm{F}$. Conversely, three weeks after the soil temperature fell below $52^{\circ}$ a rapid diminution of cases took place. The experiments to which we have already referred were as follows, and their object was to ascertain if the soil of St. Helens offered a suitable nidus for the growth of the enteric fever bacillus. In order to ascertain this point three patches of soilapparently in situ-were liberally sown with a diluted broth culture of enteric fever organisms, and later three other patches were similarly sown. The organisms grew and flonrished during June, July, and August, while the weather was dry and there was abundant sunshine. Similarly during September and October, when the weather was wet and dull, the organisms were still plentiful. In addition to these experiments other patches of soil were sown at $a$ depth of from nine to eighteen inches below the surface, and, what is a most interesting and instructive point, it was found that in every instance the organism had grown to the surface within two months. Again, another most suggestive point, it was found that in the case of all the samples by Nov. 20th the organisms could no longer be detected in the specimens of soil in which they were sown. As Dr. Robertson points out, it is by no means improbable that during the summer (the present time), when the temperature of the soil is favourable to the growth of the organism, its presence will again be discovered, and thus there may be furnished an object lesson of the manner in which enteric fever may disappear from a locality in the winter and re-appear with the heat of the following summer; in a word, Dr. Robertson considers that the soil pollution of St. Helens is a most potent cause of enteric fever in that place, and he furnishes statistics in support of that view. Dr. Robertson has also made some investigations to ascertain whether the degree of bacterial activity going on in the soil held any relation to the prevalence of enteric fever, and the amount of carbonic acid was taken as a measure of such activity. These observations are being extended, as also, it seems, are others in connexion with the height of the ground water in relation to the prevalence of enteric fever. The value of the serum diagnosis of enteric fever is spoken of very highly by Dr. Robertson, and he furnishes many instances in his report where this test cleared up existing doubts. The blood of forty-six persons was examined, and the conclusions are set forth in five groups. Group 1. Blood from persons in good health, who had never suffered from enteric fever. Results negative in every case. Group 2. Persons in good health, but who had, one to thirteen years previously, suffered from enteric fever. All of these-with the exception of one man who had gone through a typical attack of the disease a year previouslygave a definite reaction. Group 3. Patients suffering from diseases which were definitely not enteric fever. All save one case gave negative results ; and this case, although the first test gave a positive result, subsequently yielded negative results, so that Dr. Robertson thinks there may have been an error in the test. Group 4. Patients suffering from undoubted attacks of typhoid fever. Nine cases were examined, and in each one a well-marked reaction was obtained. Group 5. This was the most important group, as it contained all the doubtful cases. Of 21 cases 10 gave a positive and 11 a negative result, and in each of the negative cases the result was proved correct by the subsequent history.

Durham County District.-Dr. Eustace Hill finds that in the annual reports of the district medical officers of health proper corrections are not always made in respect to the 